\title{
To Find Out the Incidence of Congenital Malformation in Pregnancies with Polyhydramnios: A Hospital Based Observational Study
}

\author{
Sunita Bishnoi ${ }^{1}$, R.K. Bishnoi ${ }^{2}$, Balgopal Singh Bhati ${ }^{3}$ \\ ${ }^{1}$ Senior Resident, Department of Obstetrics \& Gynaecology, Government Medical College \& Bangur Hospital, Pali, Rajasthan, India, ${ }^{2}$ Associate Professor \& Head, \\ Department of Paediatrics, Government Medical College \& Bangur Hospital, Pali, Rajasthan, India, ${ }^{3}$ Assistant Professor, Department of Obstetrics \& Gynaecology, \\ Government Medical College \& Bangur Hospital, Pali, Rajasthan, India.
}

\section{Abstract}

Background: Polyhydramnios is the term for abnormal increase in the amniotic fluid. The aim of this study to find out the incidence of congenital malformation in pregnancies with polyhydramnios.. Subjects and Methods: This analytical study was conducted on 100 unselected pregnancies attending the antenatal clinic in Department of Obstetrics and Gynecology department of government Medical College and Bangur Hospital Pali, Rajasthan. Pregnancy outcome were recorded for the patients who were classified as having an excess amount of amniotic fluid. Those cases with gross congenital anomalies incompatible with life were advised termination of pregnancy after explaining the risk of procedure. Labor was induced by various methods. The fetal outcome was recorded. Results: In our study there were several confounding factors affecting the occurrence of polyhydramnios. Out of 100 cases $22(22 \%)$ were placental abruption, body weight gain of $>20 \mathrm{~kg}$ were present in 30 cases (30\%). 28 cases $(28 \%)$ were not associated with any confounding factors. Out of which $21 \%$ cases were of preterm labor, $6 \%$ were of acute abdominal pain, $7 \%$ were of PROM, $4 \%$ were of IUFD, $4 \%$ were of cord prolapsed, $5 \%$ were of $\mathrm{PPH}, 53 \%$ cases were not associated with any maternal complications. Conclusion: We concluded that amniotic fluid index is the guiding tool for early diagnosis of congenital anomalies and early obstetrics intervention. This further helps in reducing the rate of maternal complications of polyhydramnios.

Keywords: Polyhydromanios, Foetal Outcome, Maternal Outcome, Amniotic Fluid.

Corresponding Author: Dr. R.K. Bishnoi, Associate Professor \& Head, Department of Paediatrics, Government Medical College \& Bangur Hospital, Pali, Rajasthan, India.

Received: July 2019

Accepted: July 2019

\section{Introduction}

The amniotic fluid, commonly called a pregnant woman's water or waters (Latin liquor amnii), is the protective liquid contained by the amniotic sac of a pregnant female. This fluid serves as a cushion for the growing fetus, but also serves to facilitate the exchange of nutrients, water, and biochemical products between mother and fetus.

Amniotic fluid, also known as Camerons fluid is present from the formation of the gestational sac. Amniotic fluid is present in the amniotic sac. It is generated from maternal plasma, and passes through the fetal membranes by osmotic and hydrostatic forces. When fetal kidneys begin to function i.e. about in 16 weeks, fetal urine also contributes to the fluid. ${ }^{[1]}$

Polyhydramnios is the term for abnormal increase in the amniotic fluid. It is defined as "the deepest vertical pocket of greater than $8 \mathrm{cms}$ or an amniotic fluid index above $95^{\text {th }}$ percentile for gestational age". ${ }^{[2]}$ The frequency of fetal anamolies associated with polyhdramnios ranges from $31.3 \%$ to $38 \%$.

With the use of routinely performed ultrasound during pregnancy, several methods have been used to describe the amount of amniotic fluid. It has been shown that AFI is quite reliable in determining normal or elevated volumes. Nevertheless, standardised objectives indices provide accurate reproducibility and are indispensible for the monitoring of ongoing pregnancy at risk. ${ }^{[3]}$

With better facilities for detailed investigation of mother and fetus, more causative factors can be identified and this helps in the counseling of parents regarding etiology of polyhydramnios, fetal prognosis, recurrence risk and different management options for the baby if it needs medical \& surgical care after birth. ${ }^{[4]}$

\section{Subjects and Methods}

This analytical study was conducted on 100 unselected pregnancies attending the antenatal clinic in Department of Obstetrics and Gynecology department of government Medical College and Bangur Hospital Pali, Rajasthan.

\section{$\underline{\text { Inclusion Criteria }}$}

- All pregnant patients with gestational age from 16 
weeks and onwards.

- Patients having previous history

of polyhydramnios/fetal congenital malformations.

- Singleton Pregnancy.

\section{Exclusion criteria}

- Patients having family history of congenital anomalies

- Patients having history of

- Diabetes mellitus

- Hypertension

- Pre eclampsia

- Eclampsia

- Multiple pregnancy

- Hypo/hyperthyroidism.

All patients attending ANC were asked to participate at the time of booking (between 16 to 20 weeks gestation) and were subjected to USG to rule out congenital anomalies. It is necessary to carried out atleast three ultrasound scan during a normal pregnancy. The one carried out in the first trimester is diagnostic for dating the pregnancy while the purpose of the one in $3^{\text {rd }}$ trimester is useful for establishing a prognosis for vaginal delivery. Between these two the second trimester ultrasound scan is used to look form fetal malformation. However it has not always proved easy to detect fetal malformation, good no. of these has remained unseen in spite of repeated ultrasound scan. Ultrasound scan remain the only effective examination for prenatal screening of severe fetal malformations or minor fetal abnormalities.

The study population consisted of pregnant women attending the hospital in the above mentioned period, as a suspected cases of polyhdramnios, confirmation of diagnosis was always taken by the consultant obstetrician and Sonologist. Most of the cases of polyhydramnios were admitted in the hospital till they delivered, other patients were followed up as outpatient and they were admitted to the hospital for delivery.

Polyhydramnios was diagnosed when the AFI was more than 95th percentile for the gestational age. In addition, standard fetal biometric data were obtained. The fetal lie, presentation, position, assessment of gestational age and placental site were determined. A systematic fetal organ review is than performed in an attempt to detect any gross congenital abnormalities. Other necessary investigations were also carried out. Possible confounding factors that could affect the occurrence of polyhydramnios were analyzed. We than investigated the relative risks of these events to adverse perinatal outcome by adjusting the variants. All these patients had been followed up during their stay in the hospital until their discharge, by regular monitoring of fetal well being.

Pregnancy outcome were recorded for the patients who were classified as having an excess amount of amniotic fluid. Those cases with gross congenital anomalies incompatible with life were advised termination of pregnancy after explaining the risk of procedure. Labor was induced by various methods. The fetal outcome was recorded.

\section{Results}

In our study also, out of 100 patients, $56(56 \%)$ were in the age group of 21-25 yrs, $19(19.0 \%)$ were in the age group of $<20$ yrs, $25(25.0 \%)$ were above the age of 25 yrs [Table 1]. Out of 100 cases, $68.0 \%$ (68) fetuses were alive at birth, $21.0 \%$ (21) were still birth and $11.0 \%$ (11) were IUD [Table 2].

In our study there were several confounding factors affecting the occurrence of polyhydramnios. Out of 100 cases $22(22 \%)$ were placental abruption, 9 (9\%) were of past history of fetal death, $11(11 \%)$ were of past history of preterm delivery, body weight gain of $>20 \mathrm{~kg}$ were present in 30 cases (30\%). 28 cases (28\%) were not associated with any confounding factors [Table 3].

In our study there were various maternal complications, out of which $21 \%$ cases were of preterm labor, $6 \%$ were of acute abdominal pain, $7 \%$ were of PROM, $4 \%$ were of IUFD, $4 \%$ were of cord prolapsed, $5 \%$ were of $\mathrm{PPH}, 53 \%$ cases were not associated with any maternal complications [Table 4].

Table 1: Severity of Polyhydraminios according to Age

\begin{tabular}{|l|l|l|l|l|}
\hline \multirow{2}{*}{ Age (Yrs) } & \multicolumn{2}{|c|}{ Severity of Polyhydraminios } & \multirow{2}{*}{ Total (\%) } \\
\cline { 2 - 4 } & Mild & Moderate & Severe & \\
\hline$<20 \mathrm{yrs}$ & 12 & 5 & 2 & $19(19.0 \%)$ \\
\hline $21-25 \mathrm{yrs}$ & 35 & 12 & 9 & $56(56.0 \%)$ \\
\hline$>25 \mathrm{yrs}$ & 14 & 6 & 5 & $25(25.0 \%)$ \\
\hline
\end{tabular}

Table 2: Fetal Outcome Associated with Severity of Polyhyraminios

\begin{tabular}{|l|l|l|l|l|}
\hline \multirow{2}{*}{ Fetal Outcome } & \multicolumn{3}{|c|}{ Severity of Polyhydraminios } & \multirow{2}{*}{ Total (\%) } \\
\cline { 2 - 4 } & Mild & Moderate & Severe & \\
\hline Live Birth & 43 & 19 & 6 & $68(68.0 \%)$ \\
\hline Still Birth & 2 & 14 & 5 & $21(21.0 \%)$ \\
\hline IUD & 1 & 5 & 5 & $11(11.0 \%)$ \\
\hline
\end{tabular}

Table 3: Significant confounding factors affecting the occurrence of polyhydramnios

\begin{tabular}{|l|l|l|}
\hline Confounding factors & $\begin{array}{l}\text { Polyhydramnios } \\
\text { No. of cases }\end{array}$ & $\%$ \\
\hline Placental abruption & 22 & $22 \%$ \\
\hline Past history of fetal death & 9 & $9 \%$ \\
\hline Past history of pretermdelivery & 11 & $11 \%$ \\
\hline Maternal Body weight gain of $>20 \mathrm{~kg}$ & 30 & $30 \%$ \\
\hline No associated factors & 28 & $28 \%$ \\
\hline TOTAL & 100 & $100 \%$ \\
\hline
\end{tabular}

Table 4: Percentage distribution according to the maternal complications

\begin{tabular}{|l|l|l|}
\hline Complications & Frequency & Percentage \\
\hline Preterm labor & 21 & $21 \%$ \\
\hline Acute abdominal pain & 6 & $6 \%$ \\
\hline PROM & 7 & $7 \%$ \\
\hline IUFD & 4 & $4 \%$ \\
\hline Cord prolapse & 4 & $4 \%$ \\
\hline PPH & 5 & $5 \%$ \\
\hline No associated complication & 53 & $53 \%$ \\
\hline TOTAL & 100 & $100 \%$ \\
\hline
\end{tabular}

\section{Discussion}

In our study most of the fetal congenital anomalies (58\%) 
were detected by antenatal ultrasound while $42 \%$ of the anomalies were not detected on antenatal ultrasound. According to Lawrence et $\mathrm{al}^{[5]} 2-3 \%$ of the neonates are born with an abnormality that would have been detected ultrasonographically. Dasheet $\mathrm{al}^{[6]}$ found that $11.7 \%$ of the malformations were detected on prenatal ultrasound.

In our study also, out of 100 patients, $56(56 \%)$ were in the age group of $21-25 \mathrm{yrs}, 19(19.0 \%)$ were in the age group of $<20$ yrs, 25 (25.0\%) were above the age of 25 yrs. Study conducted by Ron Belosky et al. ${ }^{[7]}$ reported the highest number of patient of polyhydramnios, 50 (47\%) were in the age group of 21-25 years which is similar to our study.

Studies conducted by Humaira and colleagues $(2006)^{[8]}$ is contradictory to our study. $51 \%$ cases were reported in between the age group of 30-39 yrs and 10\% were in the age group of $>40 y r$. AnisaFawad(2008) ${ }^{[9]}$ in the colleagues reported higher incidence in the age group between 26-30 yrs. Saadia and colleagues $(2010)^{[10]}$ reported $30 \%$ in $20-29$ $\mathrm{yr}, 53 \%$ in $30-39 \mathrm{yr}$ and $5 \%$ in $>40 \%$.

In our study majority of cases $68 \%$ had live birth and $32 \%$ were dead (still birth and IUD). Our study is similar to the study conducted by Dr. Saadia Tariq on polyhydramnios: study of causes and fetal outcome. Regarding fetal outcome $68.2 \%$ babies delivered alive, still birth $24.3 \%$, and early neonatal deaths seen in 6 babies which is mainly caused by prematurity.

In our study most common maternal complication was preterm labour 25\%. Another maternal complications were PPROM (7\%), PPH (5\%), cord prolapse (4\%), acute abdominal pain (6\%), IUFD (4\%). Ariel Many et al.study to show the association between polyhrdamnios and preterm delivery . In a study by Many et al. ${ }^{[11]}$ (1995) studied to find out the association of polyhydramnios with preterm delivery. Among 275 singleton pregnancies with polyhydramnios, the incidence of preterm delivery was $18.5 \%$, but no significant difference was seen in rate of preterm delivery with increasing severity of polyhydramnios. The rate of prematurity for those pregnancies with idiopathic hydramnios (12.6\%) was shown to be similar to the control population in the study.AnishaFawad, Brian and colleagues ${ }^{[9]}$ also reported higher incidence of PROM in patients of polyhydramnios. Brian and Hubbard, Ron Bolesky (2008) ${ }^{[8]}$ also reported higher incidence of PPH in the patients of polyhdramnios.

\section{Conclusion}

We concluded that amniotic fluid index is the guiding tool for early diagnosis of congenital anomalies and early obstetrics intervention. This further helps in reducing the rate of maternal complications of polyhydramnios.

\section{References}

1. Larsen, William J.(2001). Human Embryology ( $3^{\text {rd }}$ ed). Philadelphia, Pa: Churchill Livingstone. P.490.

2. Moor TR Cayle JE. The amniotic fluid index in normal human pregnancy. Am j Obstet Gynaecol1990;162: 1168-73

3. Volante E, Gramellini D, Moretti S, Kaihura C, Bevilacqua G. Alteration the amniotic fluid and neonatal outcome. Acta Biomed AteneoParmense 2004;75(suppl):71-754)Hill LM, Breckle R, Thomas ML, Fries JK: Polyhydramnios. Ultrasonographyically detected prevalence and neonatal outcome ObstetGynaecol 1987;69;21-25

4. Magann EF, Doherty DA, Chauhan SP, et al. How well do the amniotic index and single deepest indices(below the $3^{\text {rd }}$ and $5^{\text {th }}$ and above $95^{\text {th }}$ and $97^{\text {th }}$ percentiles)predict oligohydramnios and hydramnios ?Am J O bstet Gynaecol204;190;164-9

5. Lawrence MJ, Ford MD, Hayward T, Wilson T, congenital duedonal obstruction, early antenatal ultrasound diagnosis. PediatricSurgInt $2000 ; 16: 342-5$

6. Dashe JS, McIntire DD, Ramus RM, Santos-Ramos R, Twickler DM. Hydramnios: anomaly prevalence and sonographic detection. ObstetGynecol 2000; 100: 134-139

7. HumariaAkram, andNasir and TabindaRana :Increasing severity of polyhydramnios . A risk factor for congenital malformation. E: iomedica vol. 22, Jan -June 2006/ Bio-a11a9-11.

8. Ron Bolensky et al Incidence of polyhydramnios on general obstetrics population:Am J Obstet and Gynae :2008, 199:410

9. AnishaFawad, Shamshad and Nargis Danish: Frequency, causes and outcme of polyhydramnios Journal of Medical Sciences July December 2008, vol. 6 No.2, 106-109.

10. Saadia Tariq, SaadiaCheema, Adeela Ahmed NeelaTarique : Polyhydramnios; Study of causes and fetal outcome m professional Med J. Dec 2010;17(4):660-664.

11. Ariel Many, Hill LM, Lazebink and Martin. The association between polyhydramnios and preterm delivery; Obstet Gynecol,1995; 86:38991.

Copyright: (C) the author(s), 2019. It is an open-access article distributed under the terms of the Creative Commons Attribution License (CC BY 4.0), which permits authors to retain ownership of the copyright for their content, and allow anyone to download, reuse, reprint, modify, distribute and/or copy the content as long as the original authors and source are cited.

How to cite this article: Bishnoi S, Bishnoi RK, Bhati BS. To Find Out the Incidence of Congenital Malformation in Pregnancies with Polyhydramnios: A Hospital Based Observational Study. Asian J. Med. Res. 2019;8(3):OG07-OG09.

DOI: dx.doi.org/10.21276/ajmr.2019.8.3.OG03.

Source of Support: Nil, Conflict of Interest: None declared. 